\title{
Experimental Investigation of Welding Stresses in MWIC Weldability Test
}

\author{
Houman Alipooramirabad ${ }^{1, a}{ }^{*}$, Anna Paradowska ${ }^{2, b}$, Reza Ghomashchi ${ }^{1, c}$, \\ Nicholas Hoye ${ }^{3, \mathrm{~d}}$ and M. Reid ${ }^{2, \mathrm{e}}$ \\ ${ }^{1}$ School of Mechanical Engineering, the University of Adelaide, SA 5005, Australia \\ ${ }^{2}$ Bragg Institute, Australian Nuclear Science and Technology Organisation (ANSTO), Lucas \\ Heights, NSW 2234, Australia \\ ${ }^{3}$ University of Wollongong, Wollongong, Australia \\ ahouman.alipooramirabad@adelaide.edu.au, banp@ansto.gov.au, \\ creza.ghomashchi@adelaide.edu.au, dnicholas.hoye@gmail.com, ${ }^{\mathrm{e}}$ markr@ansto.gov.au
}

\begin{abstract}
Keywords: Residual Stress, Neutron Diffraction, HACC, MWIC Weldability, SMAW and MSAW Process
\end{abstract}

\begin{abstract}
The use of high-strength steels in the manufacture of energy pipelines, coupled with the transition to larger pipe diameters and greater wall thicknesses, has led to an increased potential for cracking including hydrogen assisted cracking of energy pipelines due to higher constraint induced stresses. In the present study, a modified version of the Welding Institute of Canada (MWIC) restraint test was used to simulate the constraint conditions of full-scale girth welds on energy pipelines, allowing the influence of welding process parameters on crack formation to be assessed. MWIC test samples of X70 grade high-strength low alloy pipeline steel were manually welded using two different welding processes, namely shielded metal arc welding (SMAW) and modified short-arc welding (MSAW). Residual strains, and hence stresses, in these samples were analysed quantitatively using neutron diffraction technique. Overall, results indicate that the modified WIC restraint test produces significant residual stresses and so is effective in constraining the root run and in consequence studying the hydrogen assisted cracking of high-strength pipeline steels.
\end{abstract}

\section{Introduction}

The construction of Australian oil and gas pipeline networks is carried out using high strength low alloy (HSLA) steel line pipe and employing Shielded Metal Arc welding (SMAW) in conjunction with hydrogen rich cellulosic consumables. The application of cellulosic electrodes at ambient temperature ensures good weld penetration and shorter construction lead time with huge cost saving [1]. The drawback however is the risk of hydrogen cracking emanating from high hydrogen content of cellulosic electrodes and the high levels of restraint as a result of clamping and lifting stresses the pipeline is subjected to during construction. The Welding Institute of Canada (WIC) test was developed more than 30 years ago to provide a simple and economical way for the assessment of weldability and risk of hydrogen assisted cold cracking. Over the past three decades it was extensively utilised by the industry to qualify pipeline welding procedures [2-5]. However, the geometry of WIC test has some shortcomings associated with the difficulty for instrumentation of the WIC for the physical measurements of strain and temperature distribution during welding. This is further exacerbated with a low success rate of achieving industry acceptable welds in the WIC test environment. The original WIC design has been modified to better represent stovepipe welding of pipelines, as shown in Fig.1. The modifications enabled better control of welding mechanics and thus achieving reasonable success rate in depositing an industry acceptable weld [6]. The new designed geometry enables easier access for instrumentation and more reproducible production of test specimens. To ensure that the modifications did not modify significantly the thermal and restraint 
conditions of the test and the results are comparable with those achieved in other studies using the WIC test, physical and Finite Element studies for the original and modified test geometries have been undertaken $[6,7]$. The results have shown that the modifications to the design have little or no influence on the thermal and mechanical properties of the test, but improve the ease with which consistently high quality samples are produced. The results have shown the modifications to the design have little or no influence on the thermal and mechanical properties of the test, but improve the ease with which consistently high quality samples are produced. The modified test procedure is now accepted for a wide range of investigations.

Due to the novelty of this weldability test, there is no report on the prediction and measurement of residual stresses, which is one of the influential factors in weld metal cracking including hydrogen assisted cold cracking (HACC), in the MWIC test. Moreover, no direct link has been established so far between the welding processes of the MWIC test and the welding stresses. To address the above issues, the current paper is focused on an investigation of the effects of welding process on residual stresses in the MWIC test. Residual stress measurements in these samples were analysed quantitatively using neutron diffraction techniques on the KOWARI strain scanner at the OPAL research facility operated by the Australian Nuclear Science and Technology Organisation (ANSTO).

\section{Experimental procedure}

\section{Details of weld deposition procedure}

The weld consumable was specified to be a E6010 electrode for the shielded metal arc welding (SMAW) with a diameter of $3.2 \mathrm{~mm}$ while for the MSAW the root pass was completed with a ER70s-6 electrode. The chemical composition of both electrodes is shown in Table.1. Four samples were fabricated, two samples was used to measure the lattice spacing $\left(\mathrm{d}_{0, \mathrm{hkl}}\right)$ in a stress free mode for both welding processes and the other two samples were used to evaluate the residual stresses for SMAW and MSAW process. The yield strength of the parent metal is $490-520 \mathrm{MPa}$.

Table 1: Chemical composition of welding consumables and parent metal

\begin{tabular}{|c|c|c|c|c|c|c|c|c|c|c|c|c|}
\hline $\begin{array}{c}\text { Chemical } \\
\text { Compositio }\end{array}$ & $\% \mathrm{C}$ & $\% \mathrm{Mn}$ & $\% \mathrm{~S}$ & $\% \mathrm{Si}$ & $\% \mathrm{P}$ & $\begin{array}{c}\% \mathrm{C} \\
\mathrm{u}\end{array}$ & $\begin{array}{c}\% \mathrm{C} \\
\mathrm{r}\end{array}$ & $\begin{array}{c}\% \mathrm{~N} \\
\mathrm{i}\end{array}$ & $\begin{array}{c}\% \mathrm{M} \\
\mathrm{o}\end{array}$ & $\begin{array}{c}\% \mathrm{~V} \\
\mathrm{~T}\end{array}$ & & $\begin{array}{c}\% \mathrm{~N} \\
\mathrm{~B}\end{array}$ \\
\hline ER 70S-6 & 0.09 & $<1.6$ & 0.007 & 0.9 & 0.007 & 0.20 & 0.05 & 0.05 & 0.05 & 0.05 & - & - \\
\hline E6010 & 0.16 & 0.62 & 0.009 & 0.1 & 0.009 & - & 0.02 & 0.2 & 0.01 & $<0.1$ & - & - \\
\hline Parent metal & 0.05 & 1.55 & 0.001 & 0.2 & 0.009 & 0.15 & 0.26 & 0.19 & 0.18 & 0.02 & 0.01 & 0.04 \\
\hline
\end{tabular}

The macrographs of both welded specimens are shown in Fig. 1. The size of the root pass along with the HAZ are clearly visible on the macrographs. The MSAW welded joint appears to be more uniform with higher weld deposition volume in contrast to the SMAW with less uniform and lower weld deposition volume. 

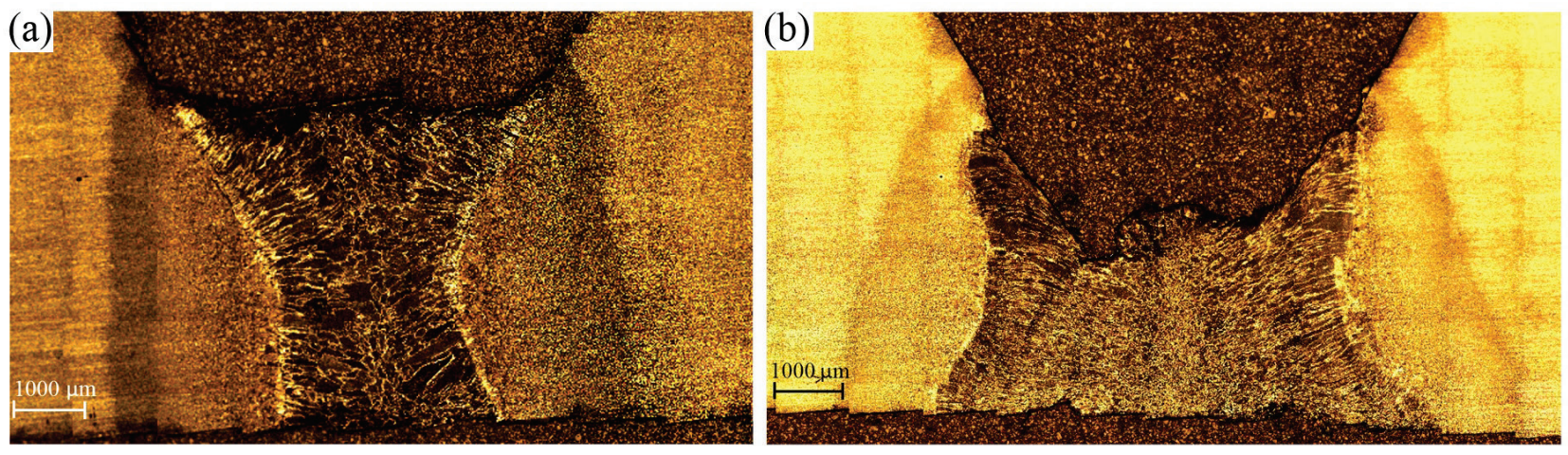

Fig. 1: Overview of MWIC root weld bead produced with (a) MSAW and (b) SMAW process

\section{Neutron diffraction}

Neutron diffraction utilises a beam of neutrons with a momentum $p$, and associated wavelength $\lambda$ :

$$
\lambda=\frac{\mathrm{h}}{\mathrm{p}}
$$

where $\mathrm{h}$ is Planck's constant. When the neutron beam penetrates crystalline materials, a diffraction pattern with sharp maxima is produced. The diffraction pattern can be described in terms of Bragg's law:

$$
2 \mathrm{~d}_{\mathrm{hkl}} \cdot \sin \theta_{\mathrm{hkl}}=\mathrm{n} \lambda,
$$

where $d_{h k l}$ are the lattice spacing, $n$ is an integer number representing the order of the reflection plane and $\theta$ is the angle between the incident ray and the scattering planes. A small change in the lattice spacing $\left(\Delta \mathrm{d}_{\mathrm{hkl}}\right)$ will result in a change in the angular position of the diffraction peak $\left(\Delta \theta_{\mathrm{hkl}}\right)$ given by the following equation:

$$
\Delta \theta_{\mathrm{hkl}}=-\tan \theta_{\mathrm{hkl}} \cdot \frac{\Delta \mathrm{d}_{\mathrm{hkl}}}{\mathrm{d}_{\mathrm{hkl}}}
$$

The lattice normal strain $\varepsilon$ is given by:

$$
\varepsilon=\frac{\mathrm{d}_{\mathrm{hkl}}-\mathrm{d}_{0, \mathrm{hkl}}}{\mathrm{d}_{0, \mathrm{hkl}}}=-\Delta \theta_{\mathrm{hkl}} \cdot \cot \theta_{0, \mathrm{hkl}},
$$

where $d_{0, h k l}$ is the strain-free lattice spacing for the hkl planes, and $\theta_{0, h k l}$ is the diffraction angle of the unrestrained lattice. The strains $\left(\varepsilon_{x x}, \varepsilon_{y y}, \varepsilon_{z z}\right)$ convert to the three-dimensional stress $\left(\sigma_{x x}, \sigma_{y y}, \sigma_{z z}\right)$ state by using the generalised Hooke's law [5]. Measurement of residual stresses were performed using the KOWARI instrument with neutron diffraction for the $\alpha$-Fe $\left(\begin{array}{lll}2 & 1 & 1\end{array}\right)$ reflection using a nominal gauge volume of $2 \times 2 \times 2 \mathrm{~mm}^{3}$. SScanSS virtual laboratory software was used in experimental design to determine the optimum sample orientations to minimise path length and hence count times during measurements. It must be noted that due to the large thickness in the support plate we have implemented a necessary machining step to achieve the desired path length of less than $80 \mathrm{~mm}$ for measurements in the transverse direction, a small $10 \mathrm{~mm}$ blind hole at 45 degree (minimal to retain the fully constrained condition) was machined in the support material as shown in Fig. 2a. Measurement points were located in along a single line running parallel to the transverse (Y) direction at $Z=1.6 \mathrm{~mm}$ in the middle of the specimen in $X$ direction. A total of 14 measurement points were used at $2 \mathrm{~mm}$ intervals to cover a total range in the transverse direction of $\pm 10 \mathrm{~mm}$ from the weld centreline. Unstrained (d-zero) measurements were performed using reference cubes $(6 \times 6 \times 6$ 
$\mathrm{mm}^{3}$ ) from the weld and parent metal. Further details of the neutron diffraction analysis to evaluate the residual stresses during welding are given in the published works of $[8,9]$.
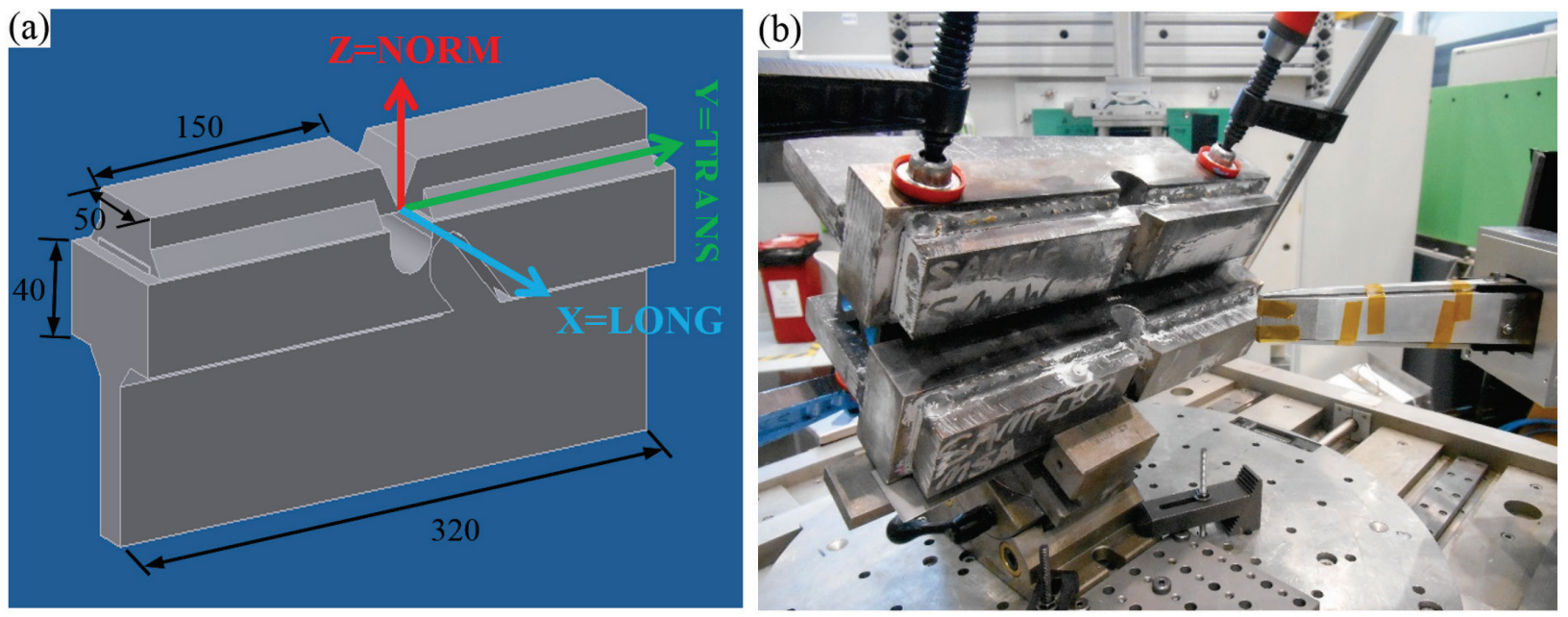

Fig.2: Experimental set up (a) Schematic and definition of coordinate system and (b) Neutron diffraction measurements of the MWIC using Kowari strain scanner at ANSTO

\section{Results and discussion}

Fig.3 (a) and (b) show the longitudinal, transverse and normal residual stresses for the MSAW and SMAW processes in the MWIC specimen. Results showed that for both processes, stresses in the transverse direction were tensile and dominant, with longitudinal stresses also predominantly tensile. In contrast, normal stresses were found to be oscillatory and comparatively low in magnitude. Measured peak stresses in the longitudinal direction were approximately equal and lower than transverse in both samples. This was due to the short weld length of $50 \mathrm{~mm}$ and lower constrained condition in that direction. These observed differences in residual stress profiles may be attributed to process effects such as energy density and deposition rate, but may also be due to observed differences in weld bead profile between the MSAW and SMAW samples causing a redistribution of stresses. In particular the apparent weld bead size is greater in the MSAW sample which can be clearly seen in Fig.1. Clearly such changes in weld size significantly change constraint conditions and hence residual stresses. As such, the measured values of stress are not directly comparable between the MSAW and SMAW samples despite them being produced with equivalent weld heat inputs. 

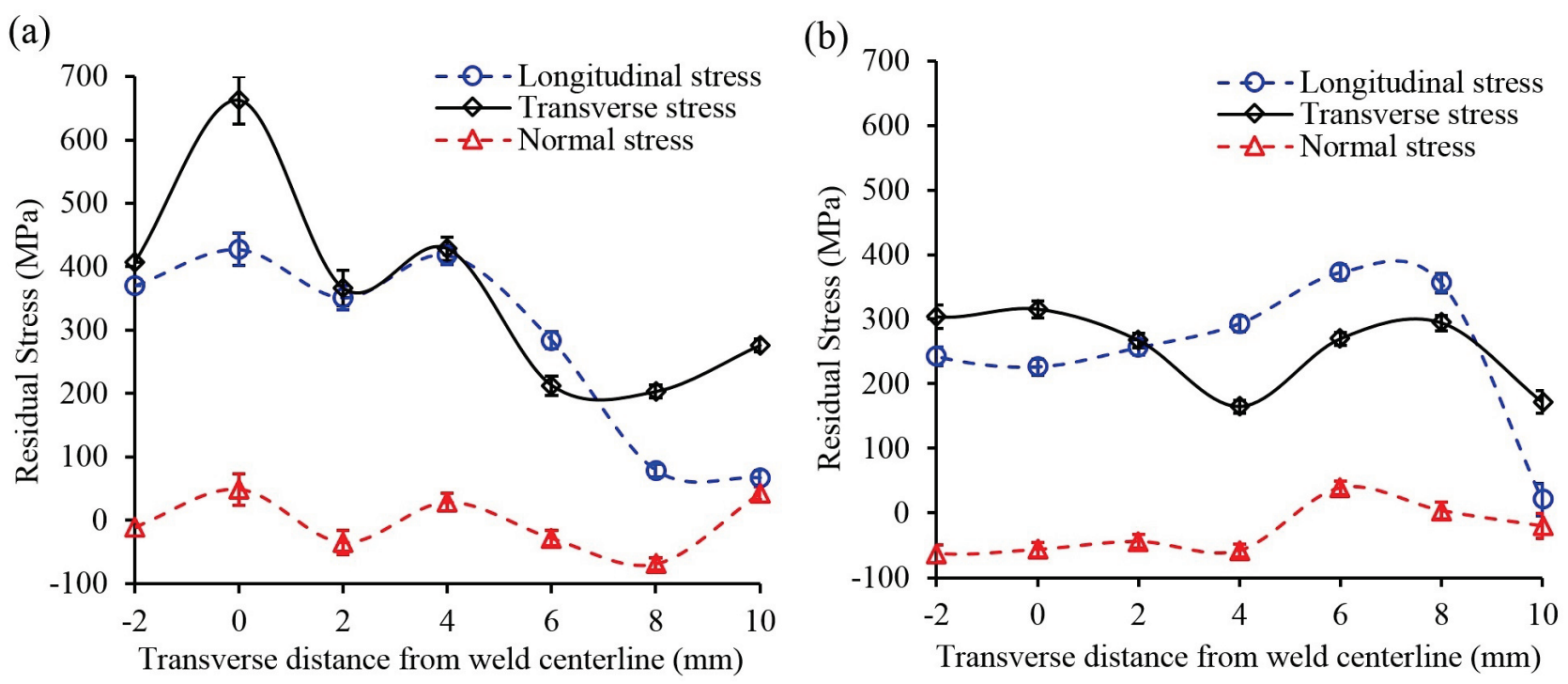

Fig.3: Residual stress measurements in samples produced with: (a) MSAW (b) SMAW processes

\section{Conclusions}

The key findings of this experimental study were:

- Highest tensile residual stresses were found in the transverse direction, while the magnitudes of the longitudinal stresses were slightly lower due to short length of the weld.

- The transverse residual stresses were of greatest magnitude in the MSAW sample. While this may be unexpected, it could be related to the significant differences in weld profile between the MSAW and SMAW samples. The larger weld bead size in the MSAW sample could significantly change the constraint conditions and hence residual stresses.

\section{Acknowledgement}

This work was conducted with the assistance of an Australian Nuclear Science and Technology Organisation (ANSTO) facilities access award (DB3748). The welding was carried out at AWS and mechanical Engineering workshop at Adelaide University. We would like to acknowledge with gratitude the support of Mr. Neville Cornish and Ashly Blanchard, welding technician from AWS, Rahim Kurji and Pascal Symons from Adelaide University. We are also grateful to EP-CRC and APIA-RSC for providing financial assistance during the course of this study (HA).

\section{References}

[1] Kotousov A, Borkowski K, Fletcher L, Ghomashchi R. A model of hydrogen assisted cold cracking in weld metal. 2012 9th International Pipeline Conference: American Society of Mechanical Engineers; 2012. p. 329-334.

[2] Alipooramirabad H, Kotousov A, Ghomashchi R. Numerical analysis of welding stresses in WIC weldability test. 8th Australasian Congress on Applied Mechanics: ACAM 8. Engineers Australia, 2014.

[3] Yurioka N, Suzuki H. Hydrogen assisted cracking in C-Mn and low alloy steel weldments. International Materials Reviews. 1990;35:217-249. http://dx.doi.org/10.1179/imr.1990.35.1.217 
[4] Yurioka N, Yamasaki S, Morimoto H. Hydrogen effusion from high strength weld metal. Science and Technology of Welding \& Joining. 2005;10:497-502. http://dx.doi.org/10.1179/174329305X46682

[5] Alipooramirabad H, Paradowska A, Ghomashchi R, kotooussov A, Hoye N. Prediction of welding stresses in WIC test and its application in pipelines. Materials Science and Technology. 2016. p. 1-9.

[6] Kurji R, Coniglio N. Towards the establishment of weldability test standards for hydrogenassisted cold cracking. The International Journal of Advanced Manufacturing Technology. 2015;77:1581-1597. http://dx.doi.org/10.1007/s00170-014-6555-3

[7] Kurji R, Griggs J, Linton V, Barbaro F, Kotooussov A, Gamboa E, Ghomashchi R, Coniglio N. An improved Welding Institute of Canada test for evaluation of high-strength pipeline steel weldability. International Pipeline Technology Conference (06 Oct 2013-09 Oct 2013: Ostend) 2013.

[8] Alipooramirabad H, Ghomashchi R, Paradowska A, Reid M. Residual stress-Microstructuremechanical property interrelationships in multipass HSLA steel welds. Journal of Materials Processing Technology. 2016; 231:456-467. http://dx.doi.org/10.1016/j.jmatprotec.2016.01.020

[9] Alipooramirabad H, Paradowska A, Ghomashchi R, Kotousov A, Reid M. Quantification of residual stresses in multi-pass welds using neutron diffraction. Journal of Materials Processing Technology. 2015;226:40-49. http://dx.doi.org/10.1016/j.jmatprotec.2015.07.002 